Technical Note

\title{
Optimal selection of groundwater-level monitoring sites in the Zhangye Basin, Northwest China
}

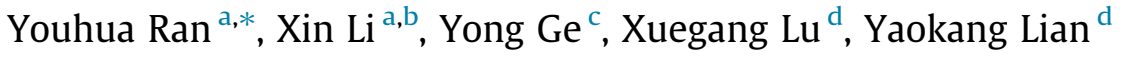

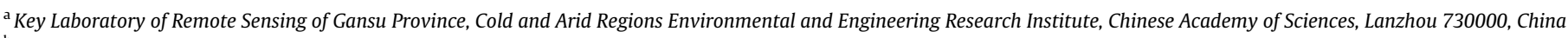 \\ ${ }^{\mathrm{b}}$ CAS Center for Excellence in Tibetan Plateau Earth Sciences, Beijing 100101, China \\ 'State Key Laboratory of Resources E' Environmental Information System, Institute of Geographical Science and Natural Resources Research, Chinese Academy of Sciences, A11, \\ Datun Road, Beijing 100101, China \\ ${ }^{\mathrm{d}}$ Heihe Water Resources and Ecological Protection Research Center, Heihe River Bureau, Yellow River Conservancy Commission of the Ministry of Water Resources, \\ Lanzhou 730000, China
}

\section{A R T I C L E I N F O}

\section{Article history:}

Received 20 February 2014

Received in revised form 26 March 2015

Accepted 30 March 2015

Available online 3 April 2015

This manuscript was handled by Peter K.

Kitanidis, Editor-in-Chief, with the

assistance of Roseanna M. Neupauer,

Associate Editor

\section{Keywords:}

Groundwater

Temporal stability

Mean of surface with non-homogeneity

Heihe River Basin

\begin{abstract}
S U M M A R Y
An optimized groundwater monitoring network is essential for agricultural irrigation that uses groundwater resources. This technical note presents a new scheme to optimize the existing groundwater-level monitoring network in the Zhangye Basin, China. The scheme integrates kriging theory, spatial stratification and temporal stability analysis. The optimized results indicate that the number of additional observation wells in each stratum is correlated with the number of existing wells, the stratum areas and the temporal stability of the groundwater-level spatial pattern. These findings are consistent with expectations. The effectiveness of the proposed method is demonstrated, and its implementation is simple, robust and flexible.
\end{abstract}

(ㄷ) 2015 Elsevier B.V. All rights reserved.

\section{Introduction}

Groundwater is an extremely important resource for agricultural, industrial and domestic use worldwide. In China, groundwater is used to irrigate more than $40 \%$ of the farmland and supplies approximately $70 \%$ of the drinking water in the dry northern and northwestern regions (Qiu, 2010). As groundwater depletion and pollution have become severe problems with the rapid economic growth and intensive resource use in China (Wang et al., 2007), groundwater monitoring of arid and semi-arid agricultural irrigation regions in Northwest China is essential. China began monitoring groundwater in the early 1950s. A fundamental network of 23,800 monitoring wells at the national, provincial and local levels has been established (He and Li, 2006). The monitoring wells are primarily boreholes that are constructed during groundwater resource investigation and that are

\footnotetext{
* Corresponding author at: 320 West Donggang Road, Cold and Arid Regions Environmental and Engineering Research Institute, Chinese Academy of Sciences, Lanzhou 730000, Gansu Province, China. Tel.: +86 931 4967964; fax: +86 931 8279161.

E-mail address: ranyh@lzb.ac.cn (Y. Ran).
}

supplemented by all types of production wells, spare wells and disabled production wells; however, the network lacks a systematic design. Although a project has been proposed to build a more extensive and sophisticated monitoring network for estimating the regional mean groundwater status, the process for selecting new monitoring well locations is challenging.

To optimize the selection of monitoring well locations, two types of approaches have been developed. The first type comprises hydrogeological approaches based on the relationships of groundwater variables with human activities, meteorological, environmental, and hydrogeological conditions, and other factors. In general, such relationships can be determined by expert knowledge, groundwater modeling and historical observations, particularly when such data are coupled with a cost-optimization model. Hydrogeological approaches are typically used for the design of groundwater monitoring networks over vast or datasparse regions (Zhou and Li, 2007), and the uncertainty in the methods is usually caused by expert subjectivity, inaccurate data, limited hydrogeological parameters for groundwater modeling and geological heterogeneity within a model grid (scaling errors) (Carrera, 1993; Baalousha and Köngeter, 2006; Nilsson et al., 
2007). The second type of optimization sampling design model includes statistical approaches that describe the spatial structure of a monitoring variable via statistical modeling and then use this information to design the network. For example, methods based on geostatistics aim to minimize the average kriging prediction-error variance; they have been widely used to design groundwater monitoring networks (Cameron and Hunter, 2002; Yeh et al., 2006; Nunes et al., 2007; Yang et al., 2008; Dhar and Datta, 2009; Nowak et al., 2010; Junez-Ferreira and Herrera, 2013). Yang et al. (2008) used the average kriging standard deviation as a criterion to determine the density of the groundwater-level monitoring network in the Chaiwopu Basin, Xinjiang Uygur Autonomous Region, China. In addition, Dhar and Datta (2009) proposed a methodology for the global optimal design of groundwater-quality monitoring networks using a linear mixed-integer formulation that incorporates ordinary kriging within the decision model formulation for spatially estimating contaminant concentration values. The authors also developed a method of reducing the monitoring redundancy by incorporating the inverse-distance weighting method for spatially interpolating concentration data (Dhar and Datta, 2010). Nowak et al. (2010) presented a task-driven optimal design scheme applying the concept of Bayesian geostatistical design to geostatistical inverse problems and also demonstrated how structural uncertainty influences optimal designs. Dhar (2013) developed a multi-objective solution based on the optimization model and the kriging model for optimally designing a groundwater head and quality monitoring plan. All of these methods were carefully developed for applications based on various types of geostatistical algorithms (Nunes et al., 2007). Second-order stationarity is assumed for the geostatistical method of groundwater monitoring in a study area, i.e., the mean and variance are independent of the location, and the covariance only depends on the lag separation. This method is appropriate for spatially homogeneous surfaces; however, in practice, this assumption is false in most regions because the groundwater level typically has a non-homogeneous surface due to the varying hydrogeological conditions and human activities. Recently, the mean of surface with non-homogeneity (MSN) method of modeling spatial means of non-homogeneous surfaces was developed (Wang et al., 2009); its validity has been tested to design gross primary production (GPP) sampling sites (Wang et al., 2014) and to optimize meteorological networks (Hu and Wang, 2011).

This technical note proposes a new scheme using the MSN to optimize the selection of groundwater-level monitoring sites in the Zhangye Basin. The interannual and seasonal variances of groundwater-level spatial patterns derived from existing observations are stratified for the MSN. This case study indicates that the proposed scheme is simple, robust and flexible for optimizing groundwater-level monitoring networks.

\section{Study area}

The Zhangye Basin, which covers an area of $1.08 \times 10^{4} \mathrm{~km}^{2}$, includes Zhangye City, Linze County and Gaotai County, as shown in Fig. 1. The basin has an arid continental climate, and the mean annual temperature is approximately $7{ }^{\circ} \mathrm{C}$. The mean annual precipitation is $117 \mathrm{~mm}$, with clear seasonal variations. The mean annual potential evaporation is $2390 \mathrm{~mm}$ (Li and Zhao, 2010). The hydrogeological characteristics of the Zhangye Basin vary from the south to the north, and they can be divided into discrete geomorphologic units, including the piedmont alluvial plain, alluvial plain, and desert. The southern region of the basin has extensive faulting with underlying bedrock, where an aquifer comprises highly permeable cobble and gravel deposits with a thickness of 300-500 m. From the northern edge of this diluvial fan, the aquifer becomes confined or semi-confined, with a thickness of 100$200 \mathrm{~m}$; it comprises interbedded cobble, gravel, fine sand, and clay. Farther north, the groundwater table becomes shallow. Additional details on the hydrogeological characteristics of the area can be found in Fan (1981) and Chen (1997).

The altitude of the Zhangye Basin ranges from 1300 to $1700 \mathrm{~m}$. A northwest-trending gradual decline occurs along the Heihe River, with an average slope of $2 \%$. The average annual water inflow of the Heihe River is approximately $1,600,000,000$ cubic meters, as measured at Yingluoxia. Approximately $70-80 \%$ of the water infiltrates the aquifer to recharge the groundwater in the piedmont area, and $60-70 \%$ of the infiltrated groundwater discharges under natural conditions in the middle and northern parts of this basin via upward seepage and springs. The annual outflow at Zhengyixia has been less than $1,000,000,000$ cubic meters since 1985.

The Zhangye Basin is an important grain-producing region in western China. The total cropland area is approximately $2000 \mathrm{~km}^{2}$. The dominant crops are seed corn, field corn, and winter wheat, the growth of which mainly relies on irrigation. The total length of the irrigation channels is approximately $4867 \mathrm{~km}$ in the Zhangye Basin (Fig. 1 shows the main channel) (Hu et al., 2008). The irrigation water is mainly sourced from the Heihe River and groundwater. According to a report from the Zhangye Water Conservancy Bureau, 5421 wells exist in this region, and 4998 wells are used for agricultural irrigation. In 2006, $3.59 \times 10^{8} \mathrm{~m}^{3}$ of groundwater was exploited, $3.06 \times 10^{8} \mathrm{~m}^{3}$ of which was used for agricultural irrigation. A groundwater-level monitoring network is urgently needed to provide reliable groundwater-level information for guiding the utilization of water resources and ensuring that such exploitation is ecologically safe for the Zhangye Basin.

\section{Methodology}

The method used here is based on the MSN, and it was developed to optimize the selection of groundwater-level monitoring sites. Specifically, the best linear unbiased estimate of the spatial mean groundwater level is determined through an iterative process based on minimum estimated mean variance criteria. MSN combines the merits of kriging and stratified sampling. The method is precise due to the appropriate zonation in stratified samples (Cochran, 1977), spatial autocorrelation, and objective and unbiased restrictions. In stratified sampling, an estimation is more precise when the within-strata variance is smaller than the between-strata variance (Cochran, 1977). The concept of temporal stability was proposed by Vachaud et al. (1985) to study soil moisture. The temporal stability used in this paper is based on the assumption that groundwater-level spatial patterns tend to persist over time within a particular landscape and geological structure. This assumption is valid at particular scales in most cases. The temporal stability of the groundwater level may be dominated by the stability of many environmental factors. Therefore, this measure is likely to be a good proxy for many environmental factors. Moreover, the temporal stability naturally combines the spatial heterogeneity of the groundwater level over a long period (see the mathematical description in Section 3.2). Temporal stability may be an excellent approach for stratifying a long-term groundwater-level monitoring network using the MSN method.

To address the nonstationarity of the groundwater level in the Zhangye Basin, the study area was divided into smaller sub-areas (strata) that were determined to be homogeneous according to the temporal stability analysis or the interannual and seasonal variance of the groundwater-level spatial patterns derived from existing observations. In the following sections, we briefly introduce MSN theory and then describe the main steps for 


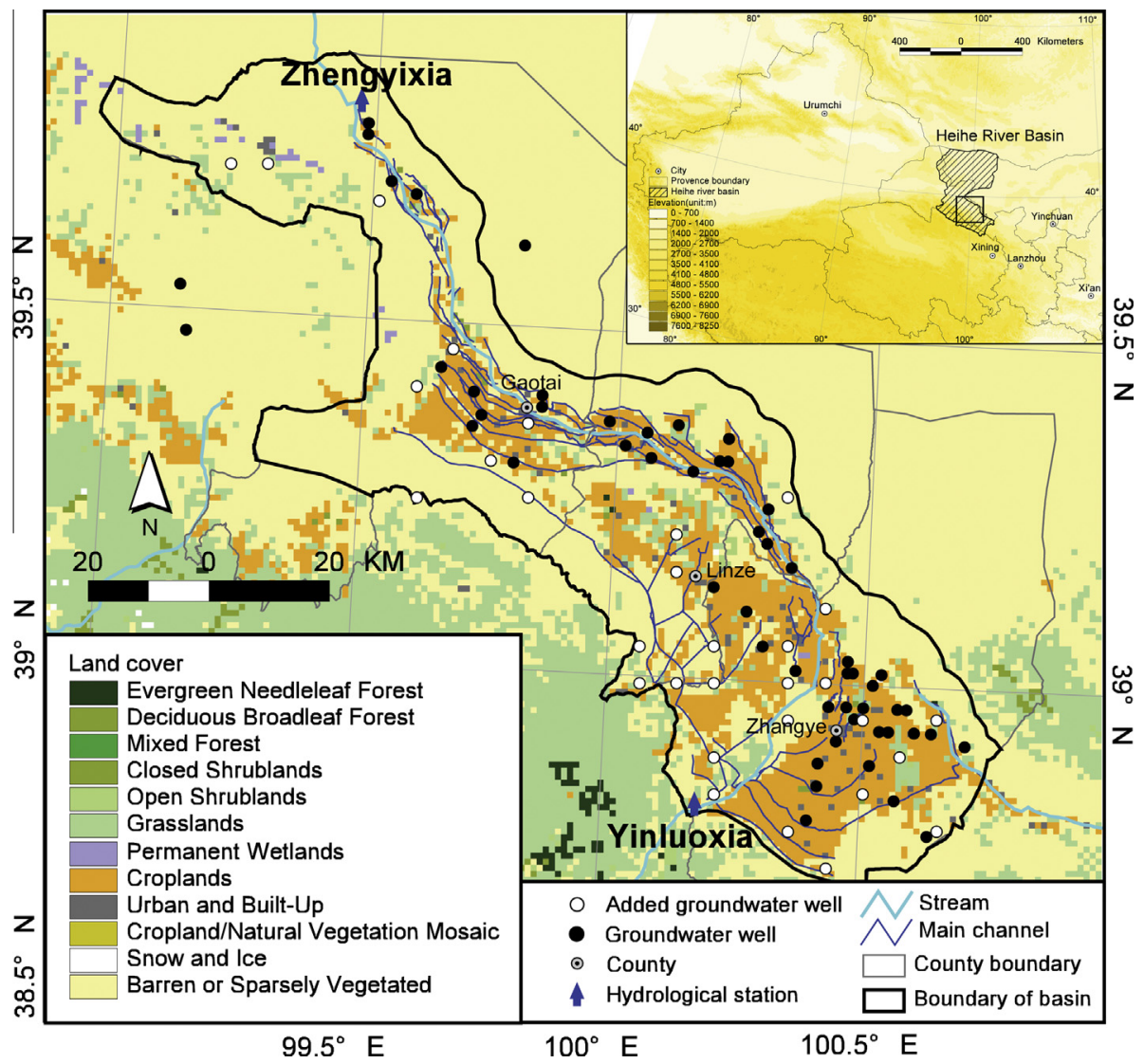

Fig. 1. The study area location, land cover and background map.

implementing the proposed method according to the flowchart shown in Fig. 2.

\subsection{Mean of surface with non-homogeneity}

MSN theory was proposed by Wang et al. (2009) for complicated surfaces to estimate the means of certain properties and their estimated variances. The theory combines spatial stratification and a

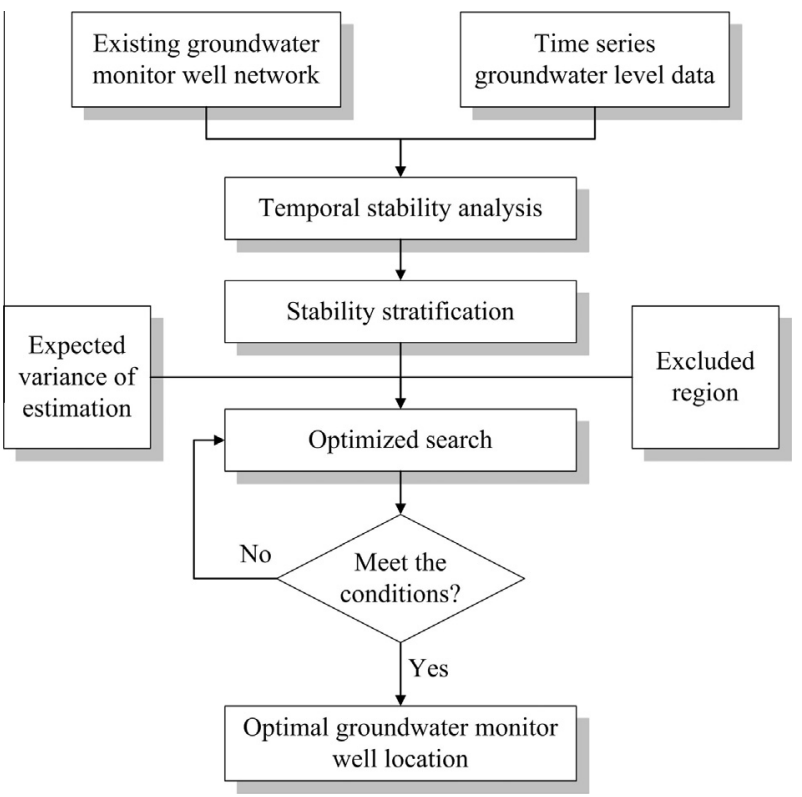

Fig. 2. Flowchart of the newly developed scheme. kriging method based on the assumption that a non-homogeneous surface can be converted into several small homogeneous surfaces by stratification (Wang et al., 2010a). MSN has been used to optimize meteorological networks (Hu and Wang, 2011) and has been conveniently and rapidly applied to optimize sampling sites in complex regions (Wang et al., 2009).

For the mathematical details on MSN, please refer to Wang et al. (2009). Here, we reproduce several key equations of the theory. In MSN, the area average of a surface can be estimated by a weighted strata mean:

$\bar{y}_{\mathfrak{R}}=\mathfrak{R}^{-1} \sum_{h=1}^{H} \mathfrak{R}_{h} \sum_{i=1}^{n_{h}} w_{h i} y_{h i}$

where the area $\mathfrak{R}$ is decomposed into a set of spatial substrata $\left\{\mathfrak{R}_{h}, h=1, \ldots, H\right\}$ within which the random field $y(s)$ is spatially homogeneous, $y_{h i}$ denotes the sample value at site $i$ within stratum $\mathfrak{R}_{h}$, and $w_{h i}$ is the corresponding weight assigned to $y_{h i}$. Stratification can be achieved using a priori information on existing groundwater observations or expert knowledge on the hydrogeological conditions of the area of interest.

The weights $w_{h i}$ are determined by solving the following equations, i.e., by minimizing the mean squared estimation error:

$$
\left.\begin{array}{l}
a_{p} \sum_{h=1}^{H} \sum_{i=1}^{n_{h}} a_{h} w_{h i} \operatorname{cov}\left(y_{h i}, y_{p j}\right)+\mu_{p}=a_{p} \Re^{-1} \int_{\mathfrak{R}} \operatorname{cov}\left(y_{p j}, y(s)\right) d s \\
\mu_{p}\left[\sum_{i=1}^{n_{p}} w_{h i}-1\right]=0 ; p=1, \ldots, H ; j=1, \ldots, n_{p}
\end{array}\right\}
$$

where $\mu_{p}$ is the Lagrangian multiplier, $a_{h}=\mathfrak{R}_{h} \mathfrak{R}^{-1}$, and $a_{p}=\mathfrak{R}_{p} \mathfrak{R}^{-1}$; $\operatorname{cov}\left(y_{h i}, y_{p j}\right)$ denotes the covariance between the $i$ th sample site within the $h$ th stratum and $j$ th sample site within the $p$ th stratum. 
If $h=p, \operatorname{cov}\left(y_{h i}, y_{p j}\right)$ expresses the spatial dependence of the surface values within the same stratum $\left(s_{i}, s_{j} \in \mathfrak{R}_{h}\right)$, and the MSN is equivalent to block kriging. If $h \neq p$, then $\operatorname{cov}\left(y_{h i}, y_{p j}\right)$ expresses the spatial dependence between the different strata $\left(s_{i} \in \mathfrak{R}_{h}, s_{j} \in \mathfrak{R}_{p}\right)$.

The corresponding mean squared estimation error can be expressed as follows:

$$
\begin{aligned}
\sigma_{\mathfrak{R}}^{2}= & \mathfrak{R}^{-2} \int_{\mathfrak{R}} \int_{\mathfrak{R}} \operatorname{cov}\left(y(s), y\left(s^{\prime}\right)\right) d s d s^{\prime}-\mathfrak{R}^{-1} \\
& \times \int_{\mathfrak{R}} \underset{h=1}{H} \sum_{i=1}^{n_{h}} a_{h} w_{h i} \operatorname{cov}\left(y_{h i}, y(s)\right) d s-\sum_{h=1}^{H} \mu_{h}
\end{aligned}
$$

The covariance model $\operatorname{cov}(\cdot, \cdot)$ is determined by fitting an adequate theoretical model to the experimental covariance values calculated in terms of previously observed groundwater-level data. Other forms of knowledge and data can also be used to develop the covariance model (Wang et al., 2009; Christakos, 2000). The error function indicates that the optimization criterion is the $\mathrm{C}$ criterion, and the most accurate and unbiased estimation of the spatial mean groundwater level can be produced from the optimized monitoring network.

The design of an optimal groundwater-level monitoring network involves determining the best sample locations that satisfy the given mean squared estimation error condition. Hu and Wang (2011) developed a software package using MSN theory to implement the spatial sampling optimization process. We utilized this software package to implement the optimal selection of groundwater-level monitoring sites.

\subsection{Implementation of the method}

\subsubsection{Step 1. Analysis of temporal stability}

The mean annual groundwater-level data of 54 wells from 1985 to 2004 and the five-day mean groundwater-level data from the Environmental and Ecological Science Data Center for West China, National Natural Science Foundation of China (http:// westdc.westgis.ac.cn), were used to analyze the temporal stability of the groundwater-level spatial pattern in the Zhangye Basin.

The standard deviation of the mean relative difference (Vachaud et al., 1985) was used to evaluate the temporal stability of the groundwater-level spatial pattern:

$\sigma\left(\delta_{i}\right)=\sqrt{\frac{1}{t-1} \sum_{j=1}^{t}\left(\frac{S_{i, j}-\bar{S}_{j}}{\bar{S}_{j}}-\bar{\delta}_{i}\right)^{2}}$

$\bar{\delta}_{i}=\frac{1}{t} \sum_{j=1}^{t} \frac{S_{i, j}-\bar{S}_{j}}{\bar{S}_{j}}$

where $S_{i, j}$ is the $j$ th sample at the $i$ th site of $n$ groundwater sample sites within the basin, and $\bar{S}_{j}$ is the computed average among all sites for a given time $j(j=1$ to $t)$. A location with a small standard deviation is considered to have a greater temporal stability in the groundwater-level spatial patterns than a location with a large standard deviation.

\subsubsection{Step 2. Stratification}

In this study, the groundwater-level dataset for 54 monitoring wells was used to analyze the temporal stability of the groundwater-level spatial pattern on annual and seasonal scales. The temporal stability was merged in this optimization process as a stratification layer. The process is described in more detail in Section 4.1 .

\subsubsection{Step 3. Determining the estimated standard deviation}

To implement the optimization process, an expected standard deviation for the optimized groundwater monitoring network must be produced. Using the current groundwater monitoring dataset, the current estimated standard deviation can be calculated. Here, a smaller standard deviation for the optimized groundwater monitoring network is sought. Therefore, the given estimated standard deviation must be smaller than the current estimated standard deviation. The desired standard deviation is a compromise between the estimation accuracy and observation costs, in which smaller standard deviations require additional observation wells after optimization. This concept is described in more detail in Section 4.2.

\subsubsection{Step 4. Optimized search}

The primary task of conducting an optimized search is to identify the best groundwater monitoring well locations from among thousands of candidates. Testing and comparing all possible combinations is impractical because of the number of monitoring sites involved. The MSN software package (Hu and Wang, 2011) accelerates the optimization process using a combined Monte Carlo and Particle Swarm Optimization (MC-PSO) algorithm. According to the given estimated standard deviation, the possible maximum number of sites $M$ was first estimated with simple sampling theory. A binary search method was then used within the range of $[0, M]$. Finally, the MC-PSO algorithm was applied to find the best candidate sites based on the minimum estimated mean variance criteria.

\section{Results and discussion}

\subsection{Temporal stability of the groundwater level in the Zhangye Basin}

Based on the groundwater-level datasets from the existing 54 monitoring wells, the variances, including the interannual and seasonal variances, were calculated according to Formula (4). The variances were then interpolated over the entire basin, as shown in Fig. 3. Fig. 3a is the interannual variability, and Fig. 3b is the seasonal change. The figures show that the interannual and seasonal stability differ. The interannual variance decreases from south to north of the Zhangye Basin, and the seasonal variance is related to the Heihe River. The reason for this variance is very complex, and many studies have focused on this topic (Wang et al., 2008; Wang et al., 2010b). The general consensus is that the variance is a result of two recharge events due to seepage of the Heihe River and irrigation water with different delay times. The differences imply that the key controls over the variance are different. For the interannual change, the key control is the geological structure, which is described in Section 2. However, for the seasonal change, the key control is an integrated factor of the hydrogeological environment and the streamflow of the Heihe River. The Heihe River mainly seeps through the riverbed along segments between Yingluoxia and Zhangyexia; this seepage is dependent on the streamflow, the river stage and the properties of the sediment in the riverbed (Wang et al., 2010b). Wang et al. (2010b) presented a simplified model to simulate the seepage of the Heihe River. Although the variation patterns of the streamflow and groundwater level are different, the highest streamflow and groundwater level are consistent throughout the year, with the highest streamflow in the midsummer and the highest groundwater level in the autumn. Therefore, the seasonal changes in the groundwater level have greater spatial heterogeneity relative to the interannual changes.

The interannual and seasonal temporal stabilities of the groundwater level were then integrated as a stratification layer 

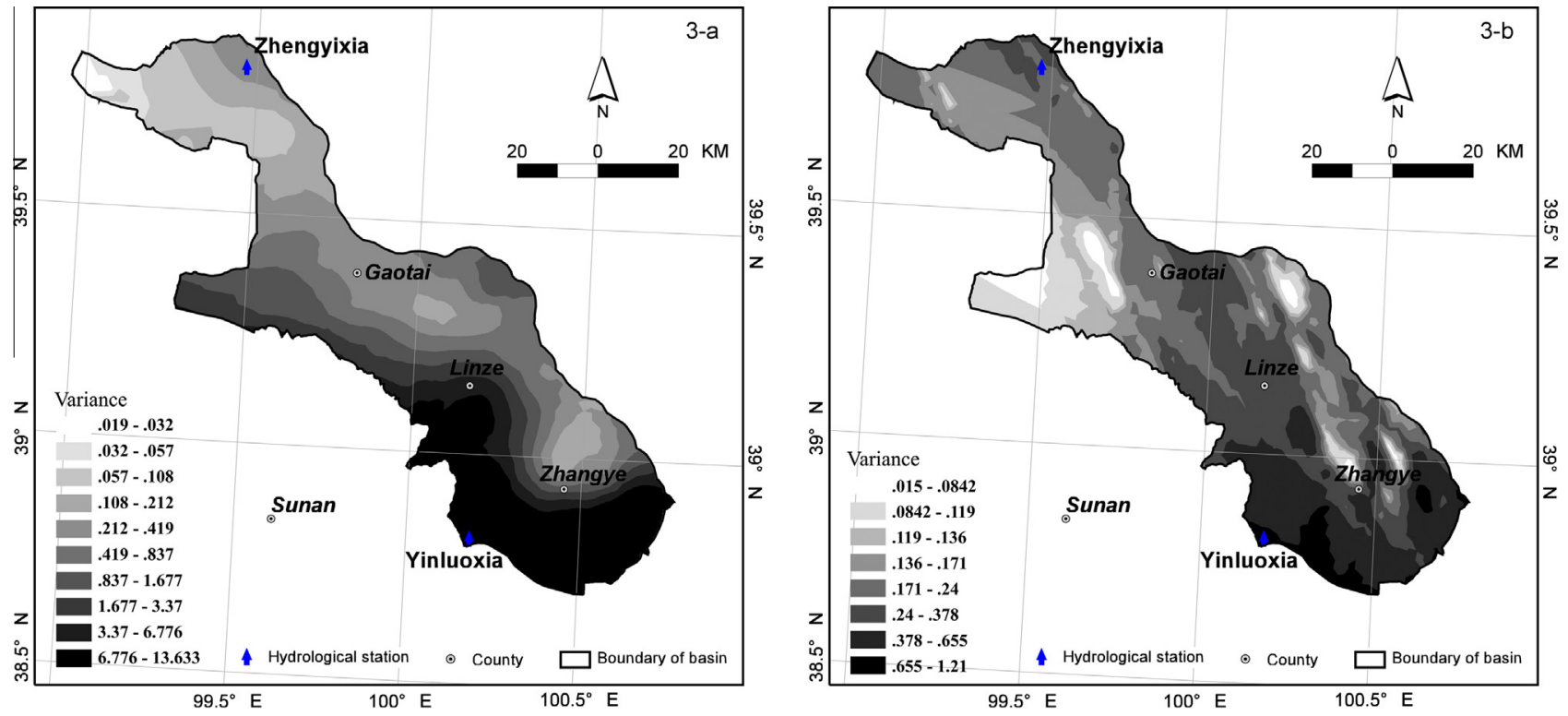

Fig. 3. The temporal stability of the groundwater level in Zhangye Basin.

(Fig. 4) so that the optimized process could be implemented by the MSN method.

\subsection{Optimal distribution and number of groundwater observation wells}

Based on the current groundwater observation network, the average groundwater level can be estimated by using the MSN method. The estimated standard deviation was calculated according to Formula (3). Given a desired standard deviation that is smaller than the current estimated standard deviation, the optimized groundwater monitoring network should include the number of additional observation wells and their spatial distribution.

Based on the current groundwater monitoring network, which includes 54 groundwater-level observation wells (the standard

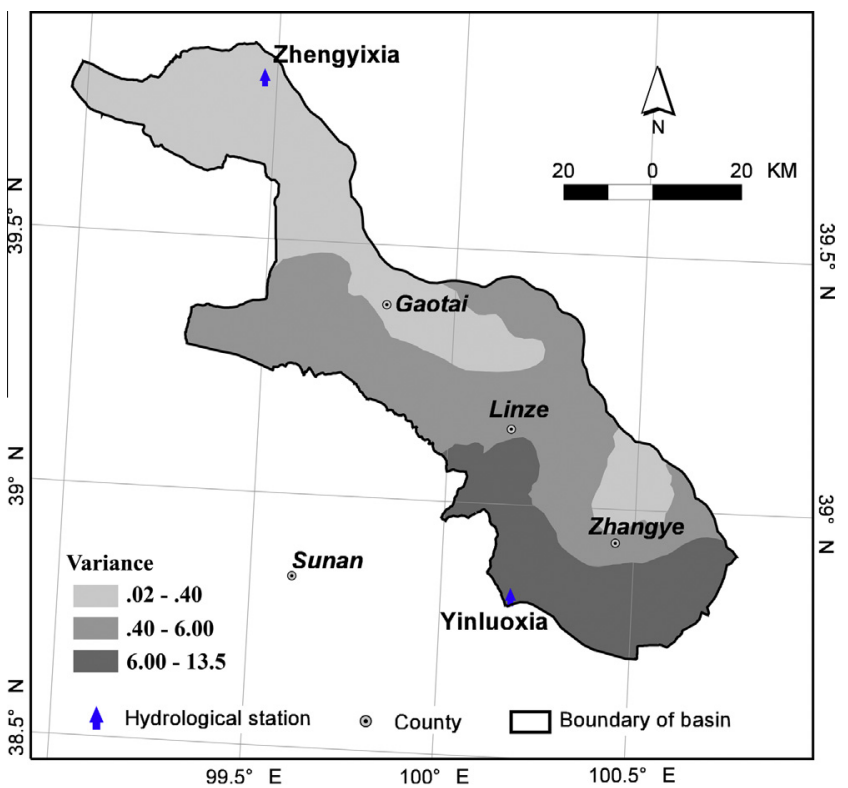

Fig. 4. The stratification for groundwater level monitoring site optimal selection according to the temporal stability of the groundwater level. deviation is 2.6 , and the sphere semi-variogram parameters were calculated), a desired standard deviation of 0.65 and the use of the temporal stability of the groundwater level as a stratification layer (Fig. 4), the groundwater-level observation network was optimized. The optimization indicated that 31 new observation wells are required; their distribution is shown in Fig. 1. Most of the new observation wells are distributed in regions that have sparse wells, such as the regions west of the Heihe River. Table 1 shows the distribution of the new observation wells in different stability strata. Although the middle-stability stratum has a similar number of existing wells and a similar area compared with the high-stability strata, it required nearly three times the number of new observation wells as the high-stability strata. The low-stability stratum required more new observation wells because it has greater spatial heterogeneity over small areas and few existing wells. These results indicate that the number of required observation wells in each stratum is correlated with the number of existing wells, the stratum area and the temporal stability of the groundwater-level spatial pattern. These results are consistent with our rational expectations for the optimized results. Certainly, these results present only one possible solution. Another optimized network may generate a different spatial distribution, but the number of wells should be similar because the possible combinations are constrained by the given standard deviation. Another test that did not include a stratification layer was conducted; the results showed that 62 new sites would be required to meet the same desired standard deviation of 0.65 and that 34 new sites would be required to meet the desired standard deviation of approximately 1 . This difference indicated that the method proposed produced a smaller number of additional wells with a smaller standard deviation. The method is suitable for optimizing the

Table 1

The distribution of the new observation wells in different stability stratum.

\begin{tabular}{lllc}
\hline Stratification type & $\begin{array}{l}\text { Num of existing } \\
\text { well }\end{array}$ & $\begin{array}{l}\text { Area } \\
\left(\mathrm{km}^{2}\right)\end{array}$ & $\begin{array}{l}\text { Num of new } \\
\text { well }\end{array}$ \\
\hline $\begin{array}{l}\text { High stability stratum } \\
\text { Middle stability }\end{array}$ & 21 & 2259.24 & 5 \\
$\quad 22$ & 2531.06 & 14 \\
$\quad$ stratum & & 1266.33 & 12 \\
Low stability stratum & 8 & & \\
\hline
\end{tabular}


distribution of the existing groundwater monitor sites using a quantitative standard. This result indicates that the effectiveness of the spatial stratification according to the temporal stability of the groundwater-level spatial pattern is based on the existing monitoring data.

Determining the desired standard deviation requires a balance between the estimation accuracy and observation costs. Fig. 5 shows the relationship between the desired standard deviation and the number of additional groundwater observation wells. This figure indicates that the number of additional observation wells increases with a decrease in the desired standard deviation. This relationship is useful for determining the desired standard deviation when optimizing future Zhangye Basin groundwater observation networks. In addition, a relationship between the number of additional observation wells and temporal stability always exists, as shown in Fig. 5. In areas of the same size that have the same number of existing monitoring wells, a lower stability stratum requires more observation wells. These results are further evidence of the feasibility of the optimization scheme proposed in this study.

\section{Summary}

In this study, we proposed a scheme for the optimal design of a groundwater monitoring network. This scheme integrates kriging theory and stratification techniques based on the assumption of a non-homogeneous groundwater-level spatial distribution. The temporal stability of the groundwater-level spatial pattern is considered a stratification in this scheme.

The scheme was used to optimize the design of a groundwaterlevel monitoring network for the Zhangye Basin. The result shows that the number of additional observation wells in each stratum was correlated with the number of existing wells, the stratum area and the temporal stability of the groundwater-level spatial pattern. In other words, when the stratum area and the number of existing wells are similar, the low temporal stability strata require more observation wells than high temporal stability strata at any given expected standard deviation. These results are consistent with our expectations. This case study demonstrates the effectiveness of this scheme for optimizing the distribution of the existing groundwater monitoring sites using a quantitative standard and shows that the implementation of the scheme is simple, robust and flexible.

However, the practical demands of a groundwater monitoring network design vary. In particular cases, multi-objective optimization poses challenges. For example, we may be concerned about water quality and quantity at the same time, but the proposed

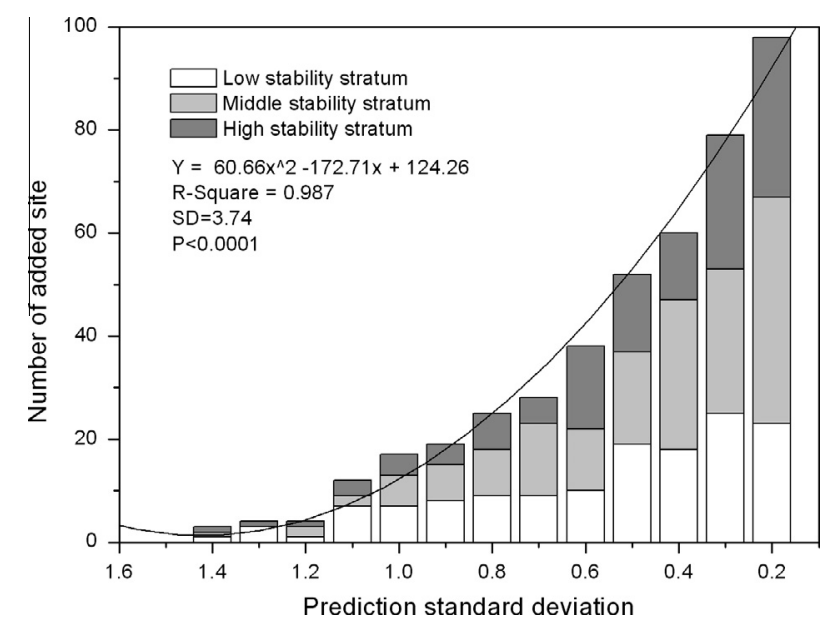

Fig. 5. The relationship among the desired standard deviation, the number of added observation wells, and temporal stability. scheme cannot be used to solve multi-objective optimization problems. Additionally, when developing an original monitoring network, if no prior data are available, the scheme is not suitable. Nonetheless, this technical note proposes a new scheme for optimizing a groundwater-level monitoring network that can be used to effectively estimate regional average groundwater states for non-homogeneous surfaces.

\section{Acknowledgments}

This study was jointly supported by the Chinese Academy of Sciences Action Plan for West Development Project "Remote Sensing Data Products in the Heihe River Basin: Algorithm Development, Data Products Generation and Application Experiments" (KZCX2-XB3-15) and National Science Foundation of China projects $(91425303,41471359)$. We thank the editor and three anonymous reviewers for their extremely helpful and constructive comments on this paper.

\section{References}

Baalousha, H., Köngeter, J., 2006. Stochastic modelling and risk analysis of groundwater pollution using FORM coupled with automatic differentiation. Adv. Water Resour. 29, 1815-1832.

Cameron, K., Hunter, P., 2002. Using spatial models and kriging techniques to optimize long-term groundwater monitoring networks: a case study. Environmetrics 13 (5-6), 629-656.

Carrera, J., 1993. An overview of uncertainties in modelling groundwater solute transport. J. Contam. Hydrol. 13 (1-4), 23-48.

Chen, M.X., 1997. The water resources related with Quaternary basin system in arid area of Northwest China. Quatern. Sci. Rev. 16, 97-104.

Christakos, G., 2000. Modern Spatiotemporal Geostatistics, 3rd ed. Oxford Univ. Press, New York, 2000.

Cochran, W.G., 1977. Sampling Techniques, 3rd ed. Wiley, New York, USA.

Dhar, A., 2013. Geostatistics-based design of regional groundwater monitoring framework. ISH J. Hydraulic Eng. 19 (2), 80-87.

Dhar, A., Datta, B., 2009. Global optimal design of ground water monitoring network using embedded kriging. Ground Water 47 (6), 806-815.

Dhar, A., Datta, B., 2010. Logic based design of groundwater monitoring network for redundancy reduction. J. Water Resourc. Plann. Manage. 136 (1), 88-94.

Fan, X., 1981. Transformation of ground-water and surface water and rational utilization of water resources in Hexi Corridor region. Hydrogeol. Eng. Geol. 4, 1-6 (in Chinese with English abstract).

He, Q.C., Li, C. 2006. Groundwater monitoring in China. In: Zhou, X.F., Li, J., Shen, H.T., et al. (Eds.). Frontiers of WWW Research and Development - APWeb 2006, Lecture Notes in Computer Science 3841, pp. 1136-1143.

Hu, M.G., Wang, J.F., 2011. A spatial sampling optimization package using MSN theory. Environ. Modell. Software 26 (4), 546-548.

Hu, X.L., Lu, L., Ma, M.G., Liu, X.J., 2008. The irrigation channel system mapping and its structure analysis for the Zhangye Oasis in the middle Heihe River Basin. Remote Sens. Technol. Appl. 23 (2), 208-213 (In Chinese with English abstract).

Junez-Ferreira, H.E., Herrera, G.S., 2013. A geostatistical methodology for the optimal design of space-time hydraulic head monitoring networks and its application to the Valle de Quer, taro aquifer. Environ. Monit. Assess. 185 (4), 3527-3549. http://dx.doi.org/10.1007/s10661-012-2808-5.

Li, S.B., Zhao, W.Z., 2010. Satellite-based actual evapotranspiration estimation in the middle reach of the Heihe River Basin using the SEBAL method. Hydrol. Process. 4 (23), 3337-3344.

Nilsson, B., Højberg, A.L., Refsgaard, J.C., Troldborg, L., 2007. Uncertainty in geological and hydrogeological data. Hydrol. Earth Syst. Sci. 11, 1551-1561.

Nowak, W., de Barros, F.P.J., Rubin, Y., 2010. Bayesian geostatistical design: taskdriven optimal site investigation when the geostatistical model is uncertain. Water Resour. Res. 46, W03535. http://dx.doi.org/10.1029/2009WR008312.

Nunes, L., Paralta, E., Cunha, M., Ribeiro, L., 2007. Comparison of variance-reduction and space filling approaches for the design of environmental monitoring networks. Computer-Aided Civil Infrastruct. Eng. 22, 489-498.

Qiu, J., 2010. China faces up to groundwater crisis. Nature 466, 308.

Vachaud, G., Silans, A.P.D., Balabanis, P., 1985. Temporal stability of spatially measured soil water probability density function. Soil Sci. Soc. Am. 49, 822-828.

Wang, J., Huang, J., Blanke, A., Huang, Q., Rozelle, S., 2007. The development, challenges and management of groundwater in Rural China. In: Giordano, M., Villholth, K.G. (Eds.), The Agricultural Groundwater Revolution: Opportunities and Threats to Development, CAB International.

Wang, G.X., Zhou, J., Kubota, J., Su, J.P., 2008. Evaluation of groundwater dynamic regime with groundwater depth evaluation indexes. Water Environ. Res. 80 (6), 547-560.

Wang, J.F., Christakos, G., Hu, M.G., 2009. Modeling spatial means of surfaces with stratified nonhomogeneity. IEEE Trans. Geosci. Remote Sens. 47 (12), 41674174. 
Wang, J.F., Haining, R., Cao, Z.D., 2010a. Sample surveying to estimate the mean of a heterogeneous surface: reducing the error variance through zoning. Int. J. Geograph. Inform. Sci. 24 (4), 523-543.

Wang, X.S., Ma, M.G., Li, X., Zhao, J., Dong, P., Zhou, J., 2010b. Groundwater response to leakage of surface water through a thick vadose zone in the middle reaches area of Heihe River Basin, in China. Hydrol. Earth Syst. Sci. 14, 639-650.

Wang, J.H., Ge, Y., Heuvelink, G.B.M., Zhou, C.H., 2014. Sampling design for estimating regional GPP with spatial heterogeneities. IEEE Geosci. Remote Sens. Lett. 11 (2), 539-543.
Yang, F.G., Cao, S.Y., Liu, X.N., Yang, K.J., 2008. Design of groundwater level monitoring network with ordinary kriging. J. Hydrodynam. 20 (3), 339-346.

Yeh, M.H., Lin, Y.P., Chang, L.C., 2006. Designing an optimal multivariate geostatistical groundwater quality monitoring network using factorial kriging and genetic algorithms. Environ. Geol. 50 (1), 101-121.

Zhou, Y.X., Li, W.P., 2007. Regional groundwater monitoring network optimization design method. Hydrogeol. Eng. Geol. 1, 1-9 (In Chinese). 